artigo ] voLume 10 | NÚMERO 21 | MAIO 2017

[PAULO DEBOM]

Doutor em História; docente da Universidade Candido Mendes.

E-mail: paulodebom@gmail.com

\title{
Worth, o precursor da alta-costura
}

\section{Worth, the haute couture predecessor}

[resumo] Diversos pesquisadores do universo da moda dedicaram algumas pá[8o] ginas de seus artigos para descrever a relevância do costureiro Charles F. Worth, principalmente por afirmarem que ele foi o pai da alta-costura. Todavia, percebe-se uma grande carência no uso de fontes primárias nesses textos. Este artigo tem por objetivo repensar o papel desse criador por meio de documentos publicados na segunda metade do século XIX.

\section{[palavras-chave]}

\section{alta-costura; Worth; fontes primárias.}

[abstract] Several researchers from the fashion world have dedicated a few pages in their articles to describe the relevance of the dressmaker Charles F. Worth, mainly by claiming that he was the father of the haute couture. However, a great lack of the use of primary sources is noticed in these texts. This article aims at rethinking the role of this creator through documents published in the second half of the nineteenth century.

[keywords] haute couture; Worth; sourcesprimaires. 


\section{Indagações}

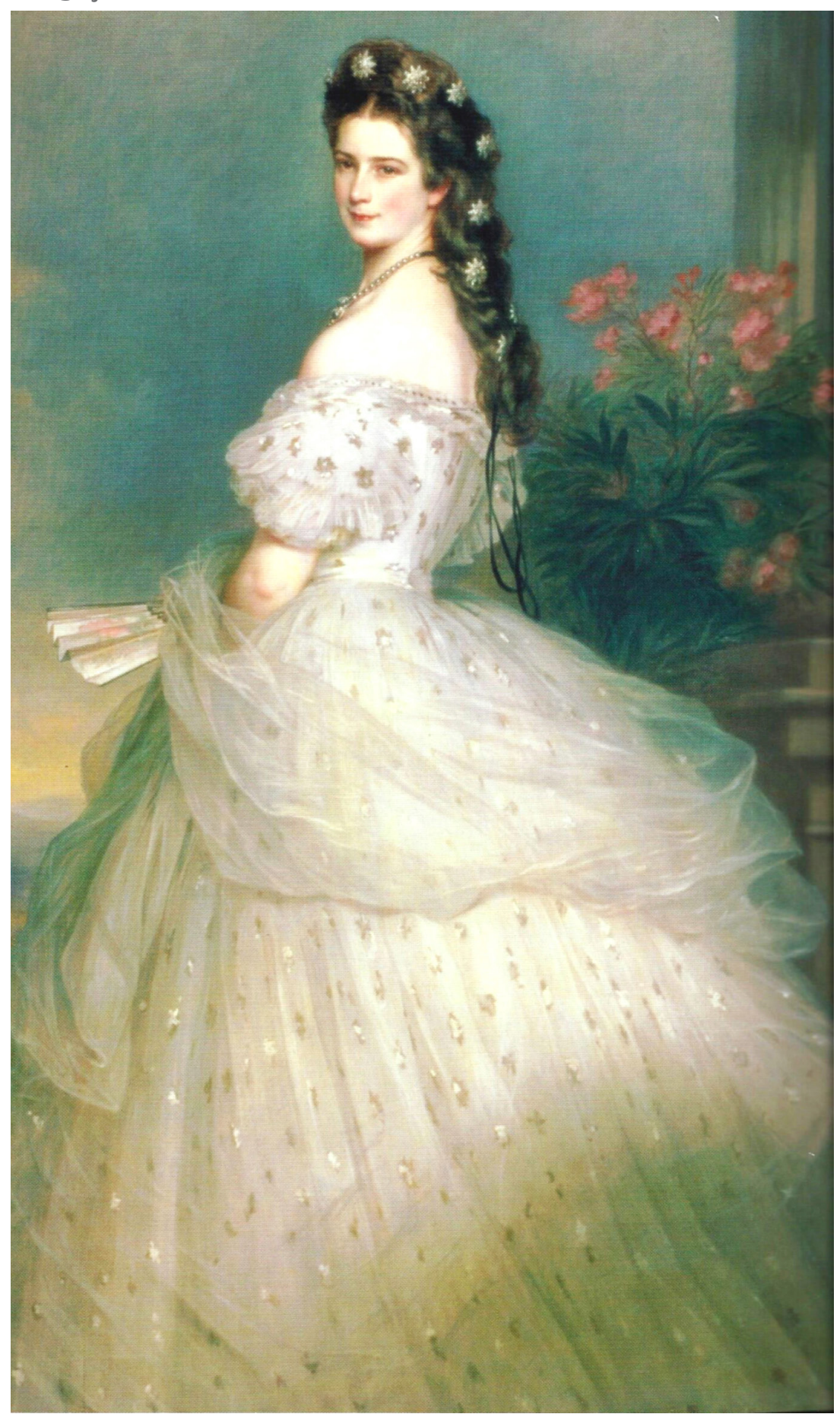

Figura 1 - Elisabeth da Áustria. Franz Xaver Winterhalter, 1865. Acervo: Museu Hofburg, Viena. Fonte: BLACK, 2012, p. 198.

0 retrato acima expõe uma personagem de grande destaque na sociedade europeia na segunda metade do século XIX, a Imperatriz Elisabeth da Áustria. Ela é representada pelas pinceladas de Winterhalter com uma postura forte $e_{\text {, ao }}$ mesmo tempo, delicada, que olha para trás como se estivesse estabelecendo uma conexão com o observador. Não há coroa e nenhum outro símbolo que remeta à sua posição social. Porém, encontra-se majestosa. Sua beleza é emoldurada por 
um vestido confeccionado especialmente para ela por Charles Frederick Worth. A roupa toma conta do cenário e fornece à imperatriz o devido status. 0 complemento vem com os diamantes que adornam seus cabelos.

Elisabeth se deslocou até o número 7 da Rue de la Paix, em Paris, para que o costureiro realizasse uma de suas criações mais famosas. Indaga-se: o que levou uma mulher tão poderosa a viajar para outro pais para obter um vestido?' Fazer encomendas de roupas de maisons parisienses era algo simples e não necessitava de deslocamento, pois os profissionais utilizavam as medidas das clientes, preparavam as peças e as enviavam. Além disso, vários de seus trajes foram feitos por costureiras na própria Áustria. Assim como Elisabeth, milhares de mulheres, de origens variadas, enfrentavam longas viagens até Paris para obter um legítimo Worth. 0 que as motivava? Antes dele, não houve nenhum outro costureiro que fosse capaz de tal façanha? Qual seu papel na História da Moda? Estas são algumas das questões que este artigo pretende dar conta.

\section{Sobre as fontes}

Charles Frederick Worth é um nome marcante para a compreensão do vestir há $159 a_{a n o s}^{2}$. Ele é citado em diversos livros e seus vestidos são apresentados em exposições. Suas criações encontram-se na reserva técnica de importantes museus, como o Metropolitan e o Museu do Brooklyn. Entretanto, quando se procuram propagandas de suas roupas nos jornais que circulavam em Paris, ao longo do período de Napoleão III, elas não aparecem, somente surgem múltiplas imagens de divulgação das maisons Gagelin, Vignon \&t Palmyre, Foucqueteau, Camille Roger, entre outras. Quadro semelhante é encontrado nas colunas de moda, nas quais há uma riquíssima descrição das silhuetas e alguns nomes de costureiros são citados frequentemente, e o de Worth surge uma vez ou outra.

Um olhar mais apurado nos manuais de História do Traje revela uma carência de referências às fontes históricas. Em suma, muito é falado sobre 0 costureiro, contudo a deficiência nas informações e reflexões apresentadas é algo explícito. Gilles Lipovetsky, em sua obra 0 império do efêmero (2002, p. 71), descreve brevemente a abertura da Maison Worth e afirma que o costureiro anunciou: "Vestidos e mantos confeccionados, sedas e altas novidades". No entanto, não indica qual é a origem da informação. No levantamento feito nos periódicos da época, nada do tipo foi encontrado. Vale destacar que existia naquele momento um número grande de jornais dedicados ao vestuário e que, diante das limitações de tempo, foi rastreada, digitalizada e analisada apenas uma parte deles. Logo, a citação do filósofo pode estar em alguma fonte não estudada, conquanto enfatiza-se que 0 autor, não somente nesse ponto de seu livro, mas em vários outros, abre aspas e não fornece a procedência. Destaca-se que existe na citação um problema ligado à tradução. Seguem duas versões e, por último, o texto original:

- Na versão brasileira: "Worth anuncia: vestidos e mantôs confeccionados, sedas, altas novidades" (LIPOVETSKY, 2002, p. 71).

- Na tradução inglesa: "Worth advertised ready-made dresses and coats, silk goods, top-nouch novelties" (LIPOVETSKY, 2002, p. 57).

- No original, em francês: "Worth affiche: robes et manteaux confectionnés, soieries, hautes nouveautés" (LIPOVETSKY, 2002, p. 83).

Os termos anuncia e advertised passam a ideia contemporânea de publicidade, logo induzem o leitor a pensar em jornal ou revista. Todavia, affiche indica 
exibir, mostrar ou expor em um cartaz. Provavelmente, a chamada foi exposta na vitrine da recém-criada loja, e não em um periódico.

Diante do vácuo nos anúncios e textos dedicados à moda, o caminho encontrado foi o estudo das colunas sociais de jornais franceses que versavam sobre o cotidiano das cerimônias da corte, como Le Monde Élégant, Musée des Familles, La Vie Parisienne e Le Moniteur des Dames et des Demoiselles 3 . Nelas, algumas das lacunas são preenchidas, pois os trajes femininos não somente eram descritos, como também eram feitas menções e críticas àqueles que os confeccionaram. Destaca-se que, em alguns jornais, a descrição das festas e das roupas era feita, porém os nomes dos costureiros não eram indicados. Também forneceram importantes dados: a coletânea de matérias do jornalista Hippolyte Taine, reunidas na obra Notes sur Paris (1867); a entrevista cedida por Worth a F. Adolphus, em 1871, para o periódico inglês Blackwood's Magazine, que se encontra descrita em detalhes no livro do jornalista Some memories of Paris (1895); as memórias da princesa Pauline de Metternich, Je ne suis pas jolie, je suis pire: souvenirs 1859-1871 (2008); o livro de Felix Whitehurst, Courtand social life in France under Napoleon III (1873); a obra Souvenirs et correspondances par Mme. Octave Feuillet (1890); os livros escritos pelos filhos de Worth, Gaston e Jean-Philipe, respectivamente La couture et la confection de vêtements de femmes (1895) e A century of fashion (1928), entre outros textos.

Ao longo dos anos 1970, a inglesa Diana de Marly, historiadora da arte e pesquisadora de indumentária formada pela Universidade de Oxford, escreveu a obra Worth: father of haute couture. 0 livro foi publicado pela primeira vez em 1980, na Inglaterra e nos Estados Unidos. A autora apresenta uma descrição detalhada da vida e da obra do costureiro. Em partes do trabalho, fornece referências a documentos da época, em especial, jornais e fotografias. Entretanto, em várias outras, principalmente nas que tangem à trajetória pessoal de Worth, não exibe fontes. Em algumas seções, o tom de romance vem à tona. Em diversos momentos, revela tons anacrônicos em suas linhas.

0 trecho abaixo mostra a descrição de um importante evento:

Assim, em um baile formal dado pelo prefeito de Paris, o Barão Haussmann, no Hôtel de Ville em 04 de fevereiro de 1866, havia uma princesa polonesa em tule branco, com um manto de veludo negro, em volta da cintura um cinto de ouro cravejado de esmeraldas (...). 0 baile foi maravilhoso!. (MARLY, 1990, p. 654, tradução nossa)

Todavia, não há a fonte indicada. 0 procedimento ocorre em diversos pontos da biografia. A trilha percorrida para minimizar o problema foi buscar as informações nas colunas sociais da época, os bailes e cerimônias sobre os quais a autora escreveu. Não foi possivel localizar exatamente o que Diana de Marly registrou, somente os mesmos eventos contados de outras formas. Há outras descrições feitas pela escritora que puderam ser confirmadas nos livros de memórias de personagens da época, como os da princesa Metternich e o da madame Octave Feuillet. Assim sendo, o entrecruzamento de diferentes textos foi o meio que viabilizou a utilização da biografia Worth: father of haute couture nesta pesquisa.

\section{O começo}

Worth iniciou seu contato com o ofício das roupas na loja inglesa de alfaiataria masculina Swan \& Edgar, onde permaneceu entre 1838 a 1845. Lá, 
trabalhou como vendedor assistente. Em 1845, ligou-se à Lewis \& Allenby, uma empresa do mesmo ramo. Nela, ocupou-se diretamente da escolha de materiais têxteis. Para tal, passou a viajar frequentemente para Lyon, Paris e Bruxelas. Além do aprendizado, as viagens aguçaram sua vontade de trabalhar com roupas femininas e também o desejo de se mudar para Paris, local onde acreditava que poderia crescer profissionalmente (MARLY, 1990; LIÑARES, 1995).

Em 1848, munido de uma excelente carta de recomendação da Lewis \& Allenby, apresentou-se em Paris ao empresário Gagelin, proprietário da Gagelin \& Obigez. Foi contratado como vendedor de tecidos. A butique, inicialmente, apenas desenvolvia o comércio têxtil. Contudo, no início dos anos 1850, abriu um departamento de alfaiataria masculina e, mais tarde, o de confecção de vestidos. Com a criação desses setores, Gagelin contratou moças, as demoiselles de magasin, para vestirem suas peças e desfilarem pela loja em horários específicos, de forma a chamar a atenção das clientes para as novidades ali produzidas, prática que deu origem aos futuros desfiles. Vale ressaltar que era também uma forma de perceber se as peças tinham um bom caimento, pois eram vistas em corpos em movimento (EVANS, 2002). As vendedoras também trajavam roupas do próprio estabelecimento. Worth e Marie Augustine Vernet, uma das demoiselles de magasin e senhora Worth, conseguiram convencer Gagelin a deixar a costura feminina sob o comando de Charles Frederick ${ }^{5}$. Inicialmente, somente lhe era permitido realizar vestimentas simples para uso diurno, no entanto, com o crescimento dos pedidos, o setor foi ampliado para os vestidos de festa (WORTH, 1895; MARLY, 1990).

Naquele momento, as Exposições Universais tomavam força no cenário europeu. Dentro de uma atmosfera de espetáculo tecnológico e comercial, a participação da França nesses eventos mostrou-se primordial. Neles, havia festas majestosas e exibições das últimas inovações das mais diversas áreas, fato que colocava os holofotes sobre a cidade que as sediava e sobre os países que participavam. Eram verdadeiras vitrines de tecnologia, luxo e consumo (PESAVENTO, 1997).

Em 1851, a Gagelin \&t Obigez participou da Exposição Universal em Londres com alguns trajes, tendo recebido elogios. Em 1855, a nova edição do evento teve lugar em Paris. A empresa marcou sua presença novamente no setor têxtil, enviando diversos vestidos que, dessa vez, foram planejados pelo costureiro inglês. Um deles recebeu a medalha de primeiro lugar. A vitória levou o nome da maison, entretanto Worth foi reconhecido em público, o que fez com que mulheres da burguesia e algumas da aristocracia desejassem obter roupas desenvolvidas por ele. Desde então, o nome do couturieringlês tornou-se cada vez mais forte na moda parisiense.

\section{Maison Worth \&t Bobergh}

Em 1857, junto com sua esposa e outro funcionário, o suiço Otto Bobergh, romperam com a Gagelin \& Obigez e abriram a maison Worth \& Bobergh no número 7 da Rue de la Paix, próximo à Place Vendôme, área de destaque no comércio de roupas. 0 pequeno estabelecimento contava com poucos funcionários e, entre eles, um número significativo oriundos da Gagelin (TÉTART-VITTU, 2012; MARLY, 1990). As vendas inicialmente eram tímidas, porém, gradativamente aumentaram. Encontrar uma brecha dentro do campo do vestuário de luxo era algo árduo. 
0 espaço social parisiense mostrava-se cada vez mais heterogêneo. 0 crescimento da metrópole, acompanhado pela industrialização, provocou maior diversificação dos inúmeros campos de forças que se digladiavam. No setor da moda, a disputa era acirrada. Não era somente Gagelin enfrentado, mas diversos nomes poderosos, como Vignon \& Palmyre, Barenne, Soinard, Delisle, Daint-Vicentt-de-Paul, Camille Roger, entre outros (Journal de Demoiselles, 1858-1860) ${ }^{6}$. Ressalta-se que, na maioria desses ateliês, as roupas femininas eram confeccionadas por mulheres, logo, Worth entrava no campo de batalha com um diferencial que poderia se virar contra ele mesmo. Entretanto, tal fato não aconteceu. Ao contrário, com o passar dos anos, o número de homens que passaram a fazer roupas para mulheres cresceu. As formas implementadas pela nova empresa de se fazer moda, aos poucos, alteraram o cenário do jogo.

Num campo, e esta é a lei geral dos campos, os detentores da posição dominante, os que têm maior capital específico, se opõem por uma série de meios aos (...) recém-chegados (...). Os antigos possuem estratégias de conservação que têm por objetivo obter lucro do capital progressivamente acumulado. Os recém-chegados possuem estratégias de subversão orientadas para uma acumulação de capital específica que supõe uma inversão mais ou menos radical do quadro de valores, uma redefinição mais ou menos revolucionária dos princípios da produção e da apreciação dos produtos e, ao mesmo tempo, uma desvalorização do capital detido pelos dominantes. (BOURDIEU, 1983, p. 2)

A nova maison tinha por objetivo vestir as mulheres dos mais altos estratos sociais franceses. Para tal, era necessário cair nas graças da imperatriz Eugênia de Montijo. Duas mulheres foram essenciais para abrir o caminho até a soberana: a madame Feuillet e a princesa Pauline de Metternich.

Em 1858, madame Feuillet, frequentadora assídua dos eventos da corte, na véspera de uma recepção imperial, recebeu de sua costureira um vestido que odiou. Na pressa para tentar resolver o problema, decidiu tentar usar algo de Worth, profissional muito bem recomendado por algumas mulheres afortunadas. Ele a recebeu pela manhã bem cedo e aceitou o desafio de preparar o traje em um espaço de tempo tão curto. Charles, Marie e madame Feuillet trocaram várias ideias e a peça foi confeccionada praticamente no corpo da cliente ao longo de um único dia. 0 cabelo e a maquiagem foram feitos no próprio ateliê, de onde a senhora saiu diretamente para a festa (FEUILLET, 1890).

Sua roupa foi extremamente elogiada por muitas pessoas e chamou a atenção da imperatriz:

Diga-me o nome de sua costureira!

Vossa majestade, ele é um homem, um inglês.

Eu não creio. Um homem? Como ele se chama?

Seu nome é Worth.

Um homem? A ideia de um homem confeccionar meus vestidos é estranha e quase indecente. (FEUILLET, 1890, p. 208) ${ }^{7}$ 
Apesar de ter elogiado a indumentária, o fato de um homem preparar roupas para uma mulher lhe soava ainda muito estranho. Naquele momento, Worth não conquistou sua cliente mais cobiçada, todavia conseguiu que seu nome chegasse aos ouvidos dela. No fim dos anos 1850, o número de homens que se dedicavam a fazer roupas para mulheres havia aumentado consideravelmente, porém, a imperatriz Eugênia era muito conservadora diante de práticas que indicassem mudanças nos padrões morais estabelecidos (MARLY, 1990; FEUILLET, 1890).

Entre 1858 e 1860, algumas senhoras oriundas da burguesia trajaram Worth em bailes aristocráticos, no entanto, para atingir a mais alta clientela e a própria esposa de Napoleão III era necessário que uma mulher que ostentasse um título de nobreza ou realeza, e que tivesse um amplo acesso à corte, trajasse suas roupas em eventos oficiais. Tentativas foram feitas sem sucesso, até que, em 1860, Marie Augustine Worth conseguiu ser recebida pela embaixatriz da Áustria, princesa Pauline de Metternich. Abaixo, a descrição do curioso encontro:

Eu estava tranquilamente instalada a ler uma manhã em minha sala quando minha criada apareceu, tendo um álbum às mãos. Eu Ihe perguntei o que ela carregava e ela me respondeu: "Há, em minha casa, uma jovem moça que gostaria que vossa alteza tivesse a bondade de dar uma olhadinha nos desenhos contidos nesse livro. São os croquis de vestidos que faz seu marido. Ele está muito interessado em vos fazer um vestido, não importa a qual preço, desde que ele vos fizesse um!".

Eu me informei sobre o nome do individuo. "Ele se chama Worth, um inglês que ousa pretender fazer toaletes femininas em Paris, uma ideia estranha, eu não os quero sob qualquer pretexto. Vossa alteza faria bem, entretanto, em olhar os croquis, replicou a criada, eles me parecem charmosos." Deixe-me ver, eu disse com um ar entediado, eu duvido que os vestidos de vosso inglês sejam do meu gosto!

Eu abri o álbum e qual não foi minha surpresa quando, na primeira página, eu vi um vestido charmoso, na segunda, um vestido encantador!... Imediatamente, eu farejei o artista e disse à minha criada: Traga-me a inglesa. - "Não é uma inglesa, é uma francesa puro sangue", foi-me respondido e, em poucos instantes, eu vi surgir madame Worth, modesta, tímida e ruborizada! Ela me disse que seu marido, que foi comissionado na Gagelin - o grande fabricante da época - acabava de se estabelecer com um sueco, um certo Bobergh, e que eles estavam instalados na Rue de la Paix, número 7; que esses senhores, muito desejosos de me contar entre suas clientes, rogavam-me por querer fazer um vestido com eles e que eu devia somente dizer o preço que gostaria de pagar. (METTERNI$\mathrm{CH}, 2008$, pp. 131-132)

A princesa de Metternich aceitou a proposta e solicitou dois vestidos, um para 0 dia e outro para a noite. Este último deveria ser muito belo e luxuoso, pois ela tinha por objetivo usá-lo no próximo baile, no palácio de Tuileries. Quanto ao preço, apenas 300 francos para cada um. A equipe da maison preparou os trajes em poucos dias. Ao recebê-los, Pauline ficou encantada com a combinação de cores e o acabamento. Disse que, com certeza, faria novas encomendas (Idem, lbidem, 2008). 
No baile, o traje foi realmente um sucesso e a resistência da imperatriz em ter um costureiro do sexo masculino foi finalmente quebrada:

A imperatriz, entrando na sala do trono onde o corpo diplomático se mantinha sempre reunido, percebeu em um piscar de olhos a obra-prima! Quando ela veio a mim, ela me perguntou em seguida quem tinha feito esse vestido tão maravilhosamente belo em sua simplicidade e elegância. "Um inglês, madame, uma estrela que se eleva ao firmamento da moda! - E qual é o seu nome? - Worth. Ah bom! Retomou a imperatriz, que a estrela tenha satélites, eu vos agradeço de lhe dizer de vir à minha casa amanhã de manhã às 10 horas!" Worth se lançara e eu estava perdida, porque a partir desse momento os vestidos de três francos não viram mais o dia! (Idem, Ibidem, [1874] 2008, p.133) ${ }^{9}$

Worth foi recebido por Eugênia. A soberana solicitou que fizesse apenas um vestido. Deixou que ele escolhesse o estilo e o material. Caso o resultado a surpreendesse positivamente, outras encomendas seriam feitas. 0 costureiro optou por fazer um vestido bege com brocados vindos de Lyon ${ }^{10}$. Ao apresentar o resultado, a imperatriz imediatamente disse não gostar de brocados. Ele explicou que mulheres elegantes usavam aquele tipo de detalhe e que os materiais vindos de Lyon estavam entre os melhores da Europa. Ela novamente afirmou que não apreciava. Todavia, Napoleão III, que até então não havia se colocado, pontuou que por motivos políticos o vestido deveria ser portado por ela em uma importante cerimônia. Lyon era uma região que concentrava uma expressiva quantidade de empresários contrários ao governo, logo, seria uma maneira de tentar uma aproximação com eles. Dessa forma, Eugênia usou não somente aquele vestido, como também outros feitos pela Worth \& Bobergh, com materiais vindos daquela província. Uma visita foi feita por ela às fábricas da região, trajando roupas específicas para que os laços entre os empresários e o imperador se estreitassem. 0 plano foi bem-sucedido tanto para o governo quanto para Worth, pois a soberana aos poucos passou realmente a apreciar as roupas e a fazer novas encomendas (Harper's Bazaar, março de 1895"11; MARLY, 1990).

A partir do sucesso obtido com a imperatriz Eugênia e a princesa de Metternich, um grande número de mulheres da aristocracia francesa $e_{1}$ posteriormente, de outros paises, dirigiram-se à nova maison para obter seus trajes. Com o aumento da produção, a confecção de trajes foi dividida em dois tipos: os que eram feitos principalmente à mão, com exclusividade para clientes específicas, ou seja, eram executados uma única vez; e os que eram preparados de forma mais mecânica e que não tinham o objetivo de serem únicos, portanto eram produzidos em número maior. Ambos, se comparados aos produtos das outras lojas, eram muito mais caros (WORTH, 1895).

A imperatriz não possuía um único costureiro, porém, vários que se dividiam entre os diferentes vestidos de que necessitava. De 1862 a 1870, o quadro de profissionais manteve-se praticamente igual: Worth, para os vestidos de cerimônias e festas; La Farrerrière, para as roupas das atividades cotidianas; Félicie fornecia capas e mantos; madames Virot e Lebel, chapéus; e Henry Creed, para os trajes esportivos. Eventualmente, ela solicitava a outras maisons, como a Gagelin, que Ihes confeccionassem roupas. Os vestidos não deveriam se repetir jamais, por esse motivo, duas vezes ao ano, Eugênia os doava para suas 
damas de honra e para as companhias de teatro e ópera. Logo, não era difícil assistir um espetáculo e identificar algo usado anteriormente pela soberana (WORTH, 1895; MARLY, 1990).

Um dos maiores privilégios que uma aristocrata poderia receber naquele período era o de ser convidada para passar um período de dias, que variava entre sete a dez, em um dos castelos imperiais fora de Paris. Nesses espaços, repetir um vestido significava nunca mais retornar ou até ser convidada a interromper a visita para voltar ao lar. Eram necessários dois trajes diários, um para o dia e o outro para a noite. Além de outros que servissem como substituto para eventuais acidentes. Havia momentos em que cerca de cem mulheres circulavam como convidadas em um château, o que significa que em média 2 mil vestidos haviam sido levados para aquele espaço (FEUILLET, 1890; MARLY, 1990).

Embora os trajes fossem feitos por diversas costureiras das melhores lojas de Paris, o mais cobiçado e o mais caro era um Worth, afinal, mulheres como a imperatriz e a princesa de Metternich o tinham como seu predileto. Reside nesse ponto o motivo para não se encontrar nos periódicos levantados nesta pesquisa propagandas da maison Worth \&t Bobergh. As próprias mulheres faziam a divulgação ao exibirem seus trajes em eventos luxuosos. As outras casas de costura precisavam colocar seus nomes nos periódicos, entretanto, a que pertencia ao costureiro inglês, não. Outro provável motivo era o receio de que suas peças fossem copiadas, fato que ocorria com frequência com as outras maisons. Enfatiza-se que vender um produto exclusivo e não anunciado dava à marca um diferencial que provocava satisfação nas consumidoras de luxo. Em suma, a propaganda do costureiro eram as próprias clientes e o burburinho criado pelas roupas que portavam nas festas e cerimônias.

As relações entre Worth e a imperatriz tornaram-se cada vez mais próximas. Para estreitar os laços, em 1860, o símbolo da empresa, colocada nas etiquetas das roupas, passou a ser o brasão do Segundo Império (Figura 2). Com a queda de Napoleão III e o advento da Terceira República, o brasão foi retirado e também 0 de Bobergh, pois ele optou por se afastar dos negócios (Figura 3).

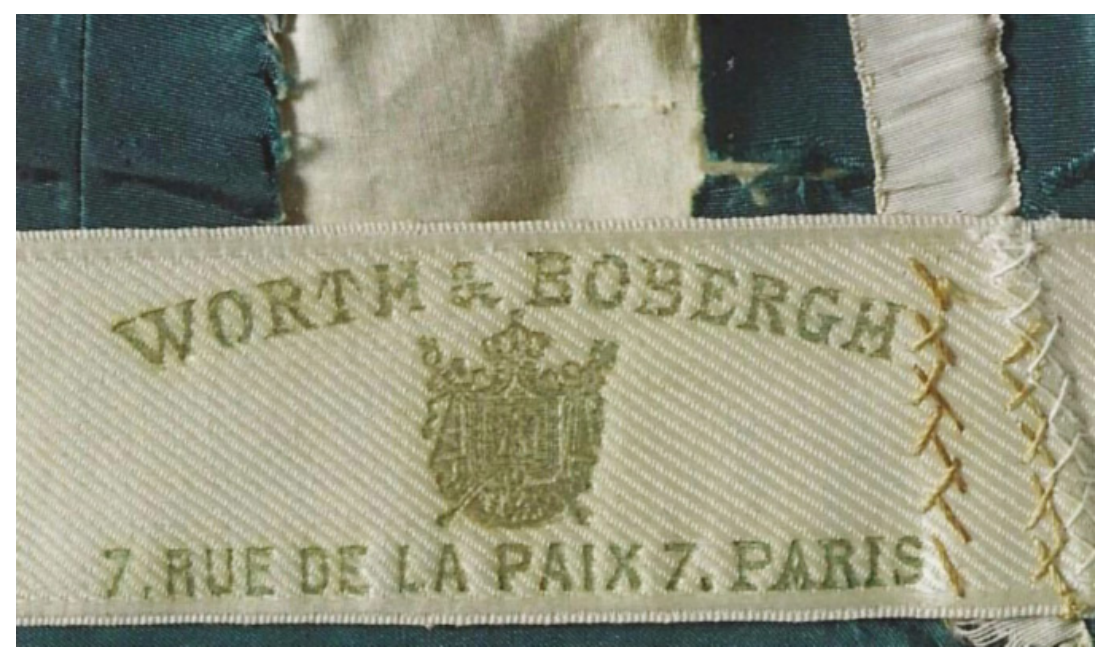

Figura 2 - Etiqueta da maison Worth \&t Bobergh, 1869. Fonte: JOIN-DIÉTERLE, Catherine, 2008, p. 179. 


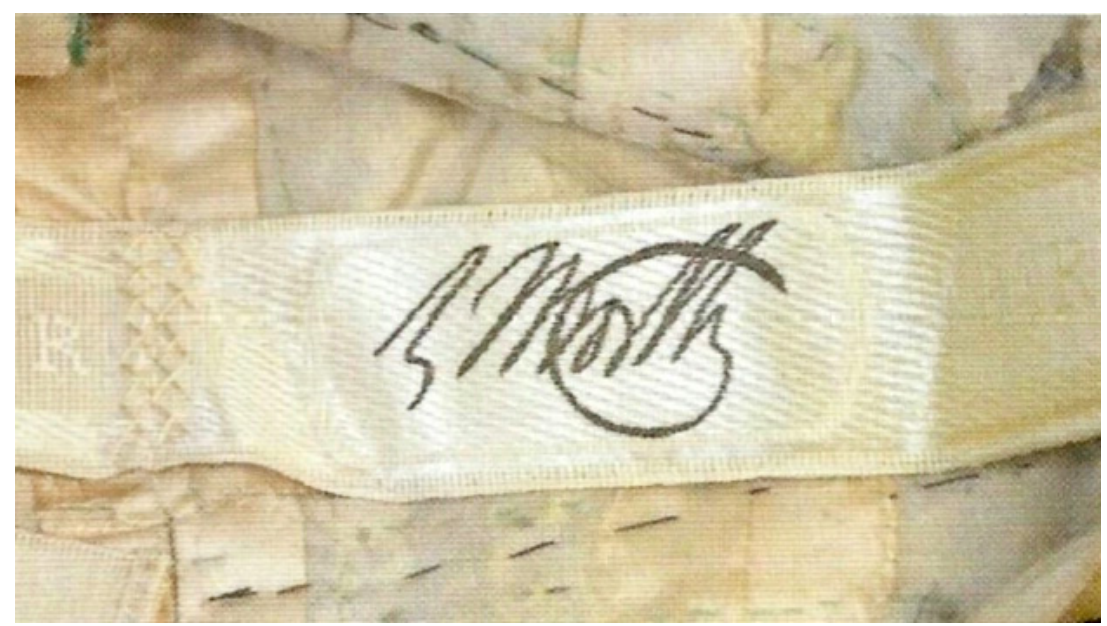

Figura 3 - Etiqueta da maison Worth após a queda do Segundo Império, 1873. Fonte: TÉTART-VITTU, Françoise, 2012, p. 28.

Ao longo da história do traje, as mudanças eram, em geral, determinadas pela realeza. Durante o século XIX, diferentes grupos de decisão passaram a influenciar as transformações no vestir. Porém, nos anos 1860, a figura do costureiro enquanto criador passou aos poucos a comandar o que deveria ou não ser moda. Até o início dos anos 1860, as clientes da aristocracia recebiam as costureiras em suas próprias residências. Na medida em que a Worth \& Bobergh se firmou no mercado de luxo, o quadro foi alterado, pois, salvo algumas exceções, eram as compradoras que se dirigiam até lá para serem atendidas. Enfatiza-se que também era necessário agendar o horário da visita. Essa prática impacientou muitas pessoas. Entretanto, trajar algo feito por aquela marca era mais importante do que qualquer incômodo.

0 crítico literário Hyppolyte Taine, em seus textos, que foram compilados na obra Notes sur Paris (1867), foi um constante detrator de Worth:

Esse pequeno ser seco, preto, nervoso, que tem ar de um prematuro arruivado ao fogo, as recebe em vareuse [tipo de casaco] de veludo, magnificamente estendido em um sofá, o cachimbo nos lábios. Ele Ihe diz: "Ande, vire-se, bem, volte em oito dias, eu comporei o vestido (...) que Ihe convém". Não eram elas que escolhiam, era ele; elas ficam muito felizes. É preciso ainda uma introdução para servir-se de sua mão. Madame Francisque B..., uma pessoa do verdadeiro mundo da elegância, veio o mês passado encomendar um vestido. - Madame, por quem me sois apresentada? - 0 que quereis dizer? - Que é preciso me ser apresentada para ser vestida por mim. Ela partiu sufocada. Outras permanecem e dizem: "Que ele seja rude, mas que me vista". (TAINE, 1867, pp. 144-145) ${ }^{12}$

Charles Dickens, editor do jornal All the Year Round, em dezembro de 1867, publicou uma interessante situação envolvendo uma senhora inglesa, Mrs. Jenkinater, ao se dirigir a um encontro com Worth sem ter sido indicada por qualquer cliente:

Talvez seu marido, em casa, Ihe tenha falado do ótimo artista inglês, que não atenderá qualquer pessoa comum se não for devidamente 
introduzida por uma distinta cliente. Mas ele estava errado: o costureiro afirma não estabelecer nenhuma distinção e nem grau. Ele é aberto a todos, como a lei. Sra. Jenkinater teve seu atendimento (...) como se fosse uma princesa. Ela é levada a uma sala de visitas, e para ela entra o senhor Worth, com um relógio na mão. Ele lança seu olhar sobre a figura da senhora, e de uma só vez "compõe um vestido". Ele sabe o que irá atendê-la da cabeça aos pés. Ele tem, em geral, teorias muito criteriosas. Com algumas das princesas magnificas que lhe dão carta branca, ele é ousado e magnífico em sua concepção. (DICKENS, 1867, p. 565) ${ }^{13}$

Walter Lonergan, em seu livro Forty years in Paris, retrata seu encontro com o costureiro:

I had been attending the marriage of the daughter of Baron and Baroness Gustave de Rothschild with Baron Leonino of Milan, a relative [...]. All Paris, and all London as well, was interested in it. As I wanted to say something about the wedding relative to the dresses of the bride and the bridesmaids, which had been designed by the renowned M. Worth, I went to see that gentleman. He was kindly (...) He was a votary of the simple life, or was at any rate what the Irish would call a "fine, honest, decent and respectable man" (...) (LONERGAN, 1907, pp.197-198) ${ }^{14}$.

0 jornalista F. Adolphus, na obra Some memories of Paris, ao encerrar sua entrevista com o estilista, relatou:

(...) Eu nunca encontrei nenhum dos Worth novamente. Mas sempre lembrei deles, e eu ainda me lembro, com uma saudável compaixão e com uma sincera gratidão pela mais gentil recepção deles para comigo. (ADOLPHUS, 1895, p. 200) ${ }^{15}$

As linhas acima, quando confrontadas, mostram algumas diferenças sobre 0 costureiro. Taine, baseado no relato de uma cliente rejeitada, afirma que somente eram atendidas as mulheres previamente indicadas. Todavia, Dickens descreve uma situação em que uma estrangeira desconhecida e sem nenhum título de nobreza foi atendida como qualquer cliente que pudesse pagar por um vestido ali confeccionado. 0 primeiro escritor mostra um homem mal-humorado e grosseiro. Já o segundo, lhe dá apenas um ar blasé. 0 terceiro autor o coloca como uma pessoa muito atenciosa e educada. Adolphus o apresenta como um lord. Em descrições de clientes - como, por exemplo, Pauline de Metternich e madame Feuillet, entre outras - ele era um profissional educado e genial. Havia em torno da imagem de Worth uma aura mítica: o empresário arrogante, estúpido e autoritário que ocupava um pedestal quase inatingivel; o artista formal, fechado e glorioso, porém, acessivel; o costureiro gentil, honesto e simples que dava a devida atenção aos seus clientes.

Havia também aqueles que viam seu trabalho como algo exagerado e que, por isso mesmo, encontrava espaço na alta sociedade. 0 jornal La Vie Parisienne, em 5 de fevereiro de 1870, publicou:

Nós não deveríamos mais dizer: A Moda, mas A Fantasia, porque hoje um traje é um mosaico lembrando várias épocas ou diversos países. Nós consagramos um gosto pelo antigo, mas sempre nos mantendo caprichosos e fantasiosos (...) Olhe, entre outras, a loja 
da Rue de la Paix; lá está um de nossos diamantes mais puros. Muito puro! Lá há luxo, o verdadeiro luxo inspirado pelo progresso de nosso Império de nosso Imperador inglês (...) ${ }^{16}$.

Em 1870, com o fim do Segundo Império, Worth fechou suas portas no mês de setembro e, por quase um ano, parou de trabalhar. A situação era extremamente instável. Ele, por ser um nome totalmente ligado ao regime derrubado, temia ser extraditado para a Inglaterra. Seu sócio, Otto Bobergh, optou por partir para a Suiça. No entanto, com o cessar dos conflitos militares, algumas esposas de importantes políticos ligados à Terceira República o procuraram para fazer encomendas. Diante do novo quadro que se estabeleceu, optou por reabrir a loja e o sucesso nos negócios retornou (ADOLPHUS, 1895). A maison se fortaleceu ao longo das décadas que se seguiram. Em 1895, Worth faleceu. "Para uma geração, o senhor Worth foi supremo em seus domínios. Ele sabia vestir uma mulher como nenhum outro sabia" (The London Times, março de 1895, APUD RILEY, 1962, p. 15) ${ }^{17}$. Seus filhos, que já estavam intimamente ligados à maison, deram prosseguimento ao trabalho do pai. Abriram filiais em Londres e Biarritz e lançaram uma linha de perfumes, entre outras realizações. 0 mercado foi muito abalado pelas duas grandes guerras e, em 1956, a família optou por fechar a empresa (RILEY, 1962, p. 15) ${ }^{18}$.

Em 2003, os empresários do ramo dos negócios de luxo, Dilesh Mehta e Martin McCarthy compraram dos herdeiros da família Worth a propriedade legal da marca. Reativaram-na lançando, inicialmente, perfumes de luxo e, em 2009, contrataram o designer Giovanni Badin - que trabalhou anteriormente com Karl Lagerfeld e Thierry Mugler - para reinventar a nova Worth, agora, com sede em Londres. 0 lançamento ocorreu na Semana de Moda de Paris do outono-inverno 2011'. A grife participou por mais dois anos do evento e, em 2013, retirou-se novamente de cena por questões financeiras.

\section{Pai da alta-costura?}

Por que Worth é considerado o primeiro criador de moda da história? Não deveria ocupar tal cargo a costureira de Maria Antonieta, madame Rose Bertin? Durante o governo de Napoleão I, o costureiro Leroy tornou-se uma personagem conhecidíssima na França. Muitos dos trajes da imperatriz Josefina e de madame Récamier foram por ele executados. Foi o costureiro mais conhecido e disputado do Primeiro Império. Pode ser colocado no mesmo patamar de Worth?

Madame Bertin pode ser considerada uma grande costureira, mas não uma criadora de moda. Ela executava peças para Maria Antonieta e era a rainha que determinava o que devia ser feito. Portanto, a margem de criação da profissional era muito limitada. Com a queda da monarquia, ela encontrou o fim de sua carreira gloriosa. 0 mesmo ocorreu com Leroy: não tinha liberdade de concepção e 0 fim do Império o retirou de cena.

Para Hans Ulrich Gumbrecht (2002, pp. 6-9):

(...) é necessário corrigir a convenção da história da moda que elevou Rose Bertin à categoria de primeira estilista de moda no mundo. (...) ela atendia os desejos de uma cliente, não produzia para um mercado, e, apesar de sua criatividade, ainda não operava num ritmo formal de mudanças. A moda tal qual a conhecemos hoje só teve início em meados dos anos 1850, com o britânico Charles Frederick Worth, o primeiro criador de uma identidade de marca (...). 
Worth possuia uma clientela variada formada por mulheres que tinham condições de pagá-lo, não importando sua origem. Os antigos costureiros tinham suas oficinas, porém, iam até suas clientes. Já Worth trabalhava basicamente em seu ateliê, atendendo raramente fora. As roupas eram idealizadas por ele e não pelas compradoras, embora atendesse os desejos de algumas delas.

De sua abertura, em 1857, até o fim do Segundo Império, em 1870, a fama da maison ultrapassou os limites da França e da própria Europa. Inicialmente, a loja contava com mais ou menos 20 funcionários, já, em 1870, em torno de 1.200. A parte externa do edifício era discreta e apenas exibia, acima da porta principal, o nome da empresa. Após cruzar a entrada do prédio, a cliente atravessava várias salas até chegar ao local do atendimento. A primeira apresentava uma exposição de matérias têxteis, sofás e cadeiras que remetiam aos interiores de palácios. A segunda, o salão arco-íris, exibia diversas amostras coloridas de seda, brocados, rendas etc. Após, deparava-se com um salão cercado por espelhos, no qual havia desenhos de trajes e manequins de madeira vestidos com peças exuberantes. A seguir, chegava-se ao cômodo no qual a cliente seria atendida: as grossas cortinas de veludo impediam a entrada do sol, a iluminação era feita por candeeiros a gás e a decoração remetia a um ambiente de baile. Lá, modelos desfilavam vestidos já prontos e também peças-piloto ${ }^{20}$. Ao escolher este último tipo, a cliente indicava alguns de seus desejos, porém, deixava a cargo de Worth a definição do real desenvolvimento do vestido. Antes da entrega final, voltava ao ateliê para fazer provas com o objetivo de evitar qualquer tipo de equívoco no produto. Além da criação de peças isoladas, foram lançadas coleções sazonais, geralmente duas por ano, em que as roupas possuiam um fio condutor entre si, ou seja, materiais, cores e acessórios seguiam uma linha definida. Destaca-se que eram realizados vários desfiles para pequenas plateias de clientes, visando apresentar uma nova coleção (COSGRAVE, 2012; MARLY, 1990).

0 número 7 da Rue de la Paix, ao longo da década de 1860, tornou-se não somente uma loja sofisticada, mas um verdadeiro palácio da moda. Apesar de a clientela aristocrática ser numerosa, as mulheres oriundas da burguesia industrial e comercial eram as mais vistas na loja. Aquele era um momento em que os grupos sociais, apesar de ainda delimitados, encontravam-se com maior frequência nos bailes e cerimônias oficiais. Ministros e influentes funcionários da corte eram originários de famílias de comerciantes e industriais (HOBSBAWM, 1988).

Ao mesmo tempo que os grandes magasins atendiam as camadas médias parisienses, o mercado de luxo também encontrou a perfeita ressonância em uma espécie de nova aristocracia em ascensão que buscava incessantemente, no campo das aparências, assemelhar-se com aqueles que possuiam títulos de nobreza. Maisons como Gagelin e Compagnie Lyonnese eram voltadas para uma clientela que desejava se distinguir das demais, logo, seus materiais eram os melhores $e_{\text {, }}$ consequentemente, os preços das roupas eram bem mais altos. Enfatiza-se que as criações de Worth eram as mais caras de Paris.

Contrariamente ao Antigo Regime, em que havia certa homogeneidade em sua formação, a elite do Segundo Império francês era composta por pessoas pertencentes a grupos muito diversos: aristocratas de estirpe comprovada, ricos comerciantes e industriais, poderosos militares, nobres que haviam recebido ou comprado seus títulos recentemente, entre outros. Apesar de a era do capital ter chegado, o governo de Napoleão III procurou construir sua imagem por meio do resgate dos valores da sociedade de corte, o que se tornava um real contrassenso.

Apesar da heterogeneidade de grupos que se estabeleceu nos setores dominantes, a burguesia, nova aristocracia que cada vez mais alcançava espaço naquele universo graças aos capitais econômico e social conquistados por meio 
do trabalho, buscava adquirir os hábitos, o vocabulário e o conhecimento que não obtiveram por meio da educação formal (capital cultural). Adotar o estilo de vida da nobreza era então crucial para se ter prestígio (capital simbólico); por meio do comportamento, do vocabulário, da etiqueta, entre outros, atingiam o status desejado.

0 gosto, propensão e aptidão à apropriação (material ou simbólica) de uma determinada categoria de objetos ou práticas classificadas e classificadoras, é a fórmula generativa que está no princípio do estilo de vida. 0 estilo de vida é um conjunto unitário de preferências distintivas que exprimem, na lógica específica de cada um dos subespaços simbólicos, mobília, vestimentas, linguagem ou hexis corporal, a mesma intenção expressiva, princípio de unidade de estilo que se entrega diretamente à intuição e que a análise destrói ao recortá-lo em universos separados. (BOURDIEU, 1983, pp. 83-84)

Ao longo da segunda metade do século $\mathrm{XIX}$ o ócio conspícuo, apesar de ainda ser valorizado, com a expansão da sociedade industrial, gradativamente passa a perder prestígio. A distinção por meio do ócio, tempo não preenchido com atividades ligadas ao trabalho, herança do Antigo Regime, fez-se presente no Segundo Império. Todavia, um grande número de integrantes da nova aristocracia obteve sua posição por meio do trabalho e desejava se aproximar dos hábitos de vida da nobreza. Ou seja, mesmo com todas as mudanças que não cessavam de ocorrer, 0 estilo de vida da antiga sociedade de corte estava na ordem do dia. A forma encontrada foi por meio da emulação, manifestada no dispêndio e na ostentação de bens com o objetivo de se destacar diante daqueles que desejavam aproximar-se e marcar de forma clara a sua distinção em relação à média e à pequena burguesia. Assim, o consumo conspícuo abriu o caminho para que os novos grupos pudessem se aproximar cada vez mais da maneira de ser dos aristocratas tradicionais. Era necessário apreender como comer, beber, ouvir o que era considerada como boa música, saber o que deveria ser lido, frequentar a ópera e comparecer aos bailes, festividades propícias para se estabelecer contatos, ver e ser visto. Todavia, de nada adiantaria tudo isso sem o melhor dos meios para se ostentar o que foi adquirido por meio do capital econômico, as roupas. Com elas, a diferença de classes tornava-se mais discreta, pois os trajes proporcionam a leitura sobre a condição pecuniária de quem os veste. Sendo assim, o consumo conspícuo, ou seja, ostensivo, levava o indivíduo à respeitabilidade pública.

A necessidade do vestuário é, pois uma necessidade "mais alta", ou seja, espiritual (...). A lei do dispêndio conspícuo orienta o consumo do vestuário, aliás, como em outras coisas, indiretamente, mediante a formação das regras do gosto e da decência. Na maioria dos casos, o motivo consciente de quem usa ou compra vestuário conspicuamente dispendioso é a necessidade (...) de viver à altura do padrão adotado no tocante ao gosto e à respeitabilidade. (...) a exigência dos gastos supérfluos está tão arraigada em nossos hábitos de pensamento (...) que qualquer outra indumentária que não é dispendiosa nos é instintivamente odiosa. (...) o barato é ordinário (...) (VEBLEN, 1985, pp.77-78).

Houve uma espécie de processo de aristocratização da burguesia. Os nobres procuravam se adaptar à nova realidade aceitando em seu seio oriundos de uma burguesia que desejava ascender socialmente. Estes procuravam apagar o rastro 
que os ligava ao comportamento de seus grupos de origem, por isso, imitavam a maneira de ser daqueles. Os poderosos comerciantes e industriais adquiriram casas de campo, colocaram seus filhos nas melhores escolas para que convivessem com a nata da sociedade e incorporassem seus gostos. Buscaram alianças por meio de casamentos com nobres, requisitaram medalhas e condecorações imperiais, compraram titulos de nobreza etc. Ou seja, tentaram ressignificar os padrões comportamentais do Antigo Regime, em meio a um continente europeu que avançava no ritmo veloz dos trens rumo ao capitalismo.

Worth, mesmo comercializando em sua loja peças confeccionadas com o uso da máquina de costura e produzidas sem caráter de exclusividade, desenvolveu um setor de criação em que os vestidos eram costurados principalmente à mão, nas medidas das clientes e com a garantia de que não haveria reprodução do traje para nenhuma outra mulher. Ele atendeu os anseios de senhoras da nobreza que desejavam se distinguir de todo o resto e também de muitas de origem burguesa que buscavam ascensão social. Em um período no qual a produção se tornava cada vez mais mecanizada, seu trabalho mostrou-se um resgate do artesanal em uma linha semelhante ao que era produzido na moda antes da Revolução Industrial.

Colocar etiquetas com o nome do fabricante em peças de roupas e acessórios não foi uma invenção que ocorreu no Segundo Império. Desde os anos 1820, já eram encontradas lojas que tinham essa prática. Entretanto, percebe-se que foi ao longo do Segundo Império que esse procedimento se cristalizou, como um meio encontrado na época para evitar falsificações (TÉTART-VITTU, 2012). Worth não foi o primeiro a etiquetar seus produtos, entretanto, ao se tornar um dos principais costureiros da imperatriz, colocou o brasão do Império como logomarca, fato que deu a seus produtos um fator de diferenciação no mercado. As outras maisons não utilizaram a mesma imagem, porém buscaram criar as suas. Junto às demais inovações que o inglês trouxe para seu campo de disputa, ele acabou por desenvolver a ideia de grife como existe até hoje, ou seja, uma empresa criadora e comercializadora de artigos que tem um estilo próprio, que as distingue das demais.

Usar um Worth era se distinguir dos outros. A peça possuía uma espécie de aura especial, um aspecto mágico que fazia de sua portadora alguém que se destacava das demais. As reflexões de Bourdieu, em seus artigos - Alta-costura, alta cultura (1983) e $O$ costureiro e sua grife (2007) - são, nesse ponto, elucidativas. As marcas de moda e as campanhas publicitárias cumprem muito bem aqui o seu papel, vendem aos seus clientes algo que vai além de uma roupa ou de um acessório para se colocar sobre o corpo. Os produtos carregam a força do sonho, da beleza, da magia. Não são roupas ou acessórios, mas sim bens sagrados capazes de causar nos consumidores uma transcendência inigualável, o caráter de necessidade espiritual pensado anteriormente por Veblen (1985).

A ideia de grife criada por Worth tem por base a necessidade de distinção. Suas práticas foram inovadoras por desenvolverem caminhos de fabricação do poder simbólico por meio de imposições do que mais tarde, no século XX, foram chamadas de tendências, conceito que pode ser visto como uma determinação do que deve ou não deve ser usado, do que é belo ou feio. Constituem-se como construções desenvolvidas pelos grupos de decisão que transmutam aquilo que não é indispensável em necessidades básicas, que se naturalizam no estilo de vida de uma classe (BOURDIEU, 1983).

Retoma-se aqui o título deste texto: Worth, o precursor da alta-costura. Por que precursor e não pa??

Nos jornais pesquisados, aparece o termo couture, mas não haute couture. Em 1868, foi criado a La Chambre Syndicale de la Confection et de la Couture pour Dames et Fillettes. Charles Worth participou do grupo que a fundou, mas nunca 
a presidiu. Seu filho, Gaston, dirigiu-a entre 1885 e 1888. Em 1910, houve uma separação entre a couture e $a$ confection com a fundação de La Chambre Syndicale de la Haute Couture. Novamente, Gaston marcou sua presença e se tornou o primeiro presidente do órgão. Outro filho de Worth, Jean-Philippe, esteve à frente da instituição entre 1933 e 1935 (RILEY, 1962). Em 1973, os diferentes segmentos do ramo se uniram em um único órgão novamente, no La Fédération Française de la Couture du Prêt-à-Porter des Couturiers et des Créateurs de Mode. ${ }^{21}$

As regras para que uma grife seja considerada como alta-costura foram estabelecidas no início do século XX e o termo passou a ser usado na mesma época. Os principais critérios para que uma grife possa usar o termo haute couture, segundo a Federação, são: estar registrada no órgão, ter uma sede em Paris, mesmo que seja estrangeira, confeccionar peças exclusivas e feitas em sua maior parte à mão, apresentar, em Paris, a cada estação uma coleção com roupas originais para 0 dia e para a noite. Worth não criou e muito menos seguiu essas regras. Por isso, a palavra pai, apesar de ser largamente usada, soa muito forte. Precursor é mais adequado, pois se enquadra melhor ao trabalho que desenvolveu e não diminui a importância de todas as portas que abriu.

As inovações que trouxe para o campo da moda estão marcadamente presentes na contemporaneidade e continuam a produzir um universo de sonhos e fantasia.

Recebido em: 09/01/2017

Aprovado em: 08/02/2017 


\section{NOTAS}

O periódico Le Modes Vraies, de abril de 1865, cita a visita da imperatriz a Paris e ao costureiro Worth

20 número de 159 anos tem como ponto de partida a abertura da maison Worth \& Bobergh no fim do ano de 1857.

${ }^{3}$ Esses periódicos foram levantados e digitalizados na Bibliothèque Forney, em Paris, no ano de 2014. Os códigos encontram-se nas referências deste artigo.

4 "Thus at a formal ball given by the Prefect of Paris, Baron Haussmann, at the Hôtel de Ville on 4 February 1866, there was a Polish princess in white tulle, with a robe of black velvet reaching three of my paces; round her waist a girdle of gold, studded with emeralds (...). The ball was wonderful!"

${ }^{5}$ No Primeiro Império Francês, o costureiro Hippolyte Leroy confeccionava roupas para mulheres da aristocracia, uma novidade para a época. Após a queda de Napoleão I, o ofício voltou a ser praticado somente por costureiras, pois era considerado imoral um homem ter um contato tão próximo com o corpo das clientes (MARLY, 1990, p. 41 ; LIÑARES, 1995, p. 38).

${ }^{6}$ Os nomes dessas empresas estão entre os que mais aparecem nos anúncios desse periódico de importante circulação na época da abertura da maison Worth \& Bobergh.

7 "Dites-moi le nom de votre coutourière! Votre Majesté, il est un homme, un Anglais. Je ne crois pas. Un homme? Et qu'est-ce qu'il a appelé? Son nom est Worth. Un homme? L'idée d'un homme confectionner mes robes est étrange et presque indécent."

8 "J'étais un matin tranquillement installée à lire dans mon salon, lorsque ma femme de chambre parut, tenant un album en main. Je lui demandais ce qu'elle apportait, et elle me répondit: "Il y a chez moi une jeune femme qui voudrait que Votre Altesse daignâtes jeter un coup d'œil sur les dessins contenus dans ce livre. Ce sont les croquis des toilettes que fait son mari. Celui-ci serait, très désireux de faire une robe pour vous, n'importe à quel prix, pourvu qu'il vous en fasse une!"

Je m'informai du nom de l'individu: "Il s'appelle Worth, un Anglais qui ose prétendre faire des toilettes de femmes à Paris, voilà une idée étrange, m'écriai-je, je n'en veux sous aucun prétexte. Votre Altesse ferait bien cependant de regarder les croquis, répliqua ma femme de chambre, ils me semblent charmants. Laissez voir, repris-je d'un air ennuyé, je doute fort que les toilettes de votre Anglais soient à mon goût!"

J'ouvrais l'album et quelle ne fut pas ma surprise, lorsque à la première page je vis une toilette charmante, à la seconde une toilette ravissante!... Immédiatement, je flairai l'artiste, et je dis à ma femme de chambre: "Amenezmoi l'Anglaise. - Ce n'est pas une Anglaise, c'est une Française pur sang", me fut-il répondu et, au bout de peu d'instants, je vis apparaître madame Worth, modeste, timide et rougissante! Elle me dit que son mari, qui avait été premier commis chez Gagelin - le grand faiseur de l'époque - venait de s'établir avec un Suédois, un certain Bobergh, et qu'ils étaient installés rue de la Paix, 7; que ces messieurs, très désireux de me compter au nombre de leurs clientes, me priaient de bien vouloir faire une robe chez eux et que je n'avais qu'à dire le prix que je voulais y mettre.

9 "L'impératrice, en entrant dans la salle du trône où le corps diplomatique se tenait toujours réuni pour le cercle, aperçut en un clin d'œil le chef-d'œuvre! Lorsqu'elle vint à moi, elle me demanda de suite qui avait fait cette robe si merveilleusement jolie dans sa simplicité et son élégance. "Un Anglais, madame, une étoile qui se lève au firmament de la mode! - Et quel est son nom? - Worth. - Eh bien! reprit l'impératrice, que l'étoile ait des satellites, je vous prie de lui faire dire de venir chez moi demain matin à 10 heures!" Worth était lancé et j'étais perdue, car à partir de ce moment les robes à trois francs ne revirent plus le jour.

${ }^{10}$ Seda com relevos bordados em ouro e/ou prata.

${ }^{11}$ Disponivel em: <http://www.napoleon.org/en/reading_room/article/file/471885>. Acesso em: 10 jul. 2015.

12 "Ce petit être sec (...) nerveux, qui a l'air d'un avorton roussi au feu, les reçoit en vareuse de velours, superbement étalé sur un divan, le cigarre aux lévres. II leur dit : "Marchez, tourne-vous; bien; revenez dans huit jours, je vous composerai la toillete qui vous convient". Ce n'est pas elles que choisissent, c'est lui; elles sont trop heureuses. Encore faut-il une introduction pour être senvi de sa main. Madame Francisque B..., une personne du vrai monde élegante, vient le mois dernier commander une robe. - "Madame, par qui m'êtes-vous présentée? - Que voulezvous dire? - C'est qu'il faut m'être présentée pour être habillée par moi". Elle s'en est allé suffoquée. D'autres restent en disant: "Qu'il me rudoie, mais qu'il m'habille".

13 "Perhaps her husband has told her of the great English artist at home, who will not measure any ordinary person unless properly introduced by a customer of distinction. But he was quite in error: the man-milliner professes to know no distinction nor degree. He is open to all, like the law. Mrs. Jenkinater had her appointment (..) like a princess; (...). She is shown into a drawing-room, and to her entered M. Worth, watch in hand. He throws his eye over the lady's figure, and at once "composes a dress". He knows what will suit the face and height. He has in general, very judicious theories. With some of the magnificent princesses who give him carte blanche, he is daring and splendid in his conception." Disponivel em: <http://onlinebooks.library.upenn.edu/webbin/serial?id=allyearround $>$. Acesso em: 12 out. 2014.

14 "Eu havia comparecido ao casamento da filha do barão e da baronesa Gustave de Rothschild com o barão Leonino de Milão, um parente (...) Toda Paris, assim como Londres, estavam interessados no evento. Como eu queria dizer algo sobre o casamento em relação aos vestidos da noiva e das damas de honra que foram projetados pelo renomado senhor Worth, eu fui ver esse cavalheiro. Ele foi gentil (...) Ele era um devoto da vida simples, ou foi, de qualquer maneira o que o irlandês chamaria de um "bom, honesto, decente e respeitável homem" (...)".

15 "I never met any of the Worth again. But I Always remembered them, and I remember them still, with hearty sympathy and with sincere gratitude for their most kind reception of me".

16 "On ne devrait pas plus dire: La Mode, mais La Fantasie, car aujourd'hui un costume est une mosaique rappelant plusieurs époques ou divers pays. Nous affectons du goût pour l'ancien, mais tout en restant capricieuses et fantasques (...) Regardez, entr'autres, Le Magasin de la Paix; c'ést là un de nos diamants les plus purs. Très pur! Voilá du luxe, du vrai luxe inspiré par le progrès de notre Empire et de notre Empereur anglais (...)." 
17 "For a generation M. Worth has been supreme in his own domain. He has known how to dress woman as nobody else knew how to dress her."

${ }^{18}$ Disponivel em: <http://www.worthparis.com/worth-future-generations/>. Acesso em: 12 jul. 2015.

${ }_{19}$ Disponivel em: <http://www.vogue.co.uk/fashion/autumn-winter-2011/couture/house-of-worth e http://www. wsj.com/articles/SB10001424052748703377504575650801768888146>. Acesso em: 12 jul. 2015.

${ }^{20}$ Nesta pesquisa, o termo peça-piloto faz referência a protótipos: roupas inacabadas, mas já com uma silhueta definida.

${ }^{21}$ Dados obtidos no site da própria instituição. Disponivel em: <http://www.modeaparis.com/fr>. Acesso em: 12 dez. 2014. Ver também: GRUMBACH, 2008; SAILLARD, Oliver \&t ZAZZO, 2012; COLE, 2011.

\section{REFERÊNCIAS}

\section{Periódicos}

Bibliothèque Forney (Paris)

Journal de Demoiselles, 1858-1860. PERD31RES

La Vie Parisienne, 16 de maio de 1868. PERRÉSFOLU13

La Vie Parisienne, 5 de fevereiro de 1870. PERRÉSFOLU13

Le Modes Vraies, abril de 1865. PERD34RES

Le Moniteur des Dames et Demoiselles, julho de 1855. D32RESPER

Le Moniteur des Dames et Demoiselles, 24 de fevereiro de 1859. D32RÉSPER

Le Monde Élégant, fevereiro de 1863. PERRÉSD6

Le Monde Élégant, fevereiro de 1866. PERRÉSD69

Musée des Familles, março de 1858. PERX23RÉS

Musée des Familles, junho de 1861. PERX23RÉS

Musée des Familles, fevereiro de 1864. PERX23RÉS

Fóndation Napoléon (Paris)

Harper's Bazaar, março de 1895.

Disponivel em: <http://www.napoleon.org/en/reading_room/article/file/471885>. Acesso em: 10 jul. 2015.

\section{BIBLIOGRAFIA}

ADOLPHUS, F. Some memories of Paris. New York: Henry Holt and Company, 1895.

BLACK, Alexandre et al. Fashion: the definitive history of costume and style. New York: Dorling Kindersley - Smithsonian, 2012.

Gostos de classe e estilos de vida. In: ORTIZ, Renato (org). Pierre Bourdieu: sociologia. São Paulo: Ática, 1983, pp. 82-121.

BOURDIEU, Pierre. Alta-costura, alta cultura. In: Questões de sociologia. RJ: Marco Zero Editora, 1983. Disponivel em: <http://www.unifra.br/professores/14299/bourdieu-alta-costura.pdfs. Acesso em: 23 jan. 2014.

. 0 costureiro e sua grife. In: BOURDIEU, Pierre. A produção da crença: contribuição para uma economia dos bens simbólicos. Porto Alegre: Editora Zouk, 2007, pp.113-190.

COLE, Daniel James. Heritage and innovation: Charles Frederick Worth, John Redfern and the dawn of modern fashion. In: Mode de recherch. Paris: Institut Français de la Mode, 2011, pp. 4-13.

COSGRAVE, Brownyn. História da indumentária e da moda: da antiguidade aos nossos dias. Barcelona: Editorial Gustavo Gili, 2012. 
DICKENS, Charles. All the year round. June-December, 1867. Disponivel em: <http://onlinebooks.library. upenn.edu/webbin/serial?id=allyearround $>$. Acesso em: 12 out. 2014.

Feuillet, Mme. Octave. Souvenirs et correspondances par Mme. Octave Feuillet: quelques années de ma vie. Paris: Calmann Levy Éditeur, 1890.

GUMBRECHT, Hans Ulrich. Pensando a moda: a dialética das passarelas. In: Folha de S. Paulo. São Paulo, pp. 6-9, 5 de maio de 2002.

JOIN-DIÉTERLE, Catherine (org). Sous l'empire des crinolines. Paris: Éditions Musée Galliera, 2008.

LIÑARES, Javier. Charles Frederick Worth. Datatextil. Terrasa: Centro de Documentación \& Museu Textil. Enero de 1995, pp. 37-48.

LIPOVETSKY, Gilles. 0 império do efêmero: a moda e seu destino nas sociedades modernas. São Paulo: Companhia das Letras, 2002.

LONERGAN, Walter F. Forty years of Paris. London: Fisher Unwin, 1907.

MARLY, Diana de. Worth: father of haute couture. New York-London: Holmes \& Meier, 1990.

METTERNICH, Pauline de. Je ne suis pas jolie, je suis pire: souvenirs 1859-1871. Tallandier: Paris, [1874] 2008

RILEY, Robert. The house of Worth. The Brooklyn Museum: New York, 1962

TAINE, Hippolyte. Notes sur Paris. Paris: Libraire Hachette, 1913.

TÉTART-VITTU, Françoise. The origins of haute couture. In: SAILLARD, Oliver; ZAZZO, Anne. Paris haute couture. Paris: Flammarion, 2012, pp.18-32.

VEBLEN, Thorstein. A teoria da classe ociosa: um estudo econômico das instituições. São Paulo: Abril Cultural, 1983.

[9] WHITEHURST, Félix. Court and social life in France under Napoleon III, 1873.

WORTH, Gaston. La couture et la confecction de vêtements de femmes. Paris: Imprimerie Chaix, 1895

WORTH, Jean-Philippe. A century of fashion. Boston: Little Brown and Company, 1928. 